\title{
Meditaciones morales de Descartes: pasión y auto conservación de la vida
}

\author{
GIANNINA BURLANDO \\ Pontificia Universidad Católica de Chile \\ gburlan@uc.cl
}

\begin{abstract}
Resumen
La hipótesis del presente estudio es que las meditaciones morales de Descartes incluyen una doctrina de las pasiones del alma y una concepción de la vida, ambas intrínsecamente vinculadas. Nuestro propósito será entonces: Primero, mostrar que tras el análisis del corpus cartesiano es posible reconstruir aspectos centrales de su meditación moral: que su meditación moral incluye una doctrina innovadora de las pasiones. Segundo, mostraremos que para Descartes ethos y pathos están vinculados; que este vínculo se hace explícito en sus ideas del conocimiento práctico, esto es, de una praxis que se identifica con el «ejercicio de la virtud» y del «vivre beurensement». Tercero, concluimos respondiendo a la pregunta ¿Dónde descansa la moralidad en Descartes? ¿Es para él un asunto de la pura razón? ¿Un asunto más allá de la pura razón? ¿Uno de conceptos, de juicios, de carácter, de educación, de acción y conocimiento práctico o uno de propiedades intrínsecas de las cosas o propiedades de los agentes humanos, o bien de una cierta conexión entre varios de estos?
\end{abstract}

Palabras clave: Descartes, meditaciones morales, pasión.

\section{Descartes's moral meditations: passion and life preservation}

\begin{abstract}
The hypothesis beld in the current study is that Descartes is truly concerned about moral matters; that his moral meditations involve a doctrine on the passions of the soul and a conception of life as well, both of them intrinsically tied up. Thus, my purpose is as follows: first, to show that it is possible to reconstruct crucial aspects of Descartes's moral meditations after the analysis of his corpus doctrinae: that his moral stand involves a new conception of the passions. Secondly, I shall underline that ethos y pathos are connected in his views; that this connection is explicit in Descartes's ideas of practical knowledge, namely, in the sort of praxis recon as "the exercise of virtue», the «vivre heureusements. Thirdly, I will approach the question on wherein does cartesian morality lye? ¿Is it a matter of concepts, judgments, character, education, action and practical wisdom, or rather a question of the intrinsic properties of things and human agents, or even a mixture among some of these?
\end{abstract}

Key words: Descartes, moral meditations, passions.

Master of Arts y Philosophy Doctor por la Ohio State University (Estados Unidos). Ha sido docente tanto en la Ohio State University, como en la Universidad de Chile y en la Pontificia Universidad Católica de Chile, en la que actualmente se desempeña como Profesora Asociada. También dicta Historia de la Filosofía Antigua e Historia de la Filosofía Medieval en el Seminario Pontificio Mayor de Santiago de Chile. Es autora de numerosos artículos de libros y revistas especializadas nacionales e internacionales, varios de ellos sobre Francisco Suárez y Descartes. Coeditó, junto a F. Bertelloni, el vol. 24 de la Enciclopedia Iberoamericana de Filosofía: Filosofía Medieval (2002). Es coautora, introductora y editora De las pasiones en la filosofía medieval (2009). Es Investigadora responsable de proyectos FONDECYT tales como: "Defensas históricas del poder político: Suárez y Locke teóricos de la moralidad por el acuerdo" (2011-13); "La pasión en la vida virtuosa: teorías éticas de Suárez y Descartes" (2009-11); y otros.

El presente estudio vierte resultados parciales del proyecto FONDECYT N 1095189. 
Parece tópico entre los diversos comentaristas de Descartes la convicción de que él no desarrolló teorías del valor -como estética y ética- con excepción de una cierta ética, considerada por Descartes mismo como una moral par provision. En cuanto a la estética cartesiana - aunque haya una histórica controversia entre sus comentaristas (Kranz, André, Dumont, Cousin, Becq, et al.) sobre la ausencia de una doctrina estética-, obras tales como los Praenotanda, el Compendium Musicae, son evidencia del temprano y manifiesto interés de Descartes por lo bello y lo agradable, en el contexto particular de la música. En tal contexto, como defiende P. Chiuminatto ${ }^{1}$, Descartes propone criterios y valores estéticos. Los valores estéticos revelan sus orígenes ya en la sensualidad, o ya en la geometría, así él escribe: «el deleite es fin último de la música»; mientras que sus juicios estéticos de gusto y belleza incluyen nociones de: gozo, admiración, agrado, orden, proporción, indistinción, cambio, variedad, diversidad, cognición clara y distinta, novedosa, atenta ${ }^{2}$.

En cuanto a la ética, es comúnmente aceptado, como nota J. Cottingham $^{3}$, que Descartes no es un filósofo de la moral; particularmente por sus propias y explícitas declaraciones en Los Principios de filosofía: que la construcción de un sistema moral perfecto -la plus parfaite morale - tendría que ser el coronamiento de su filosofía. Por lo mismo, se ve a Descartes enfrentando de modo general, de manera transitoria en vez de definitiva, el campo del comportamiento prudencial, y por eso, alcanzando a articular apenas «un código moral provisorio», por el que se conducirá mientras levanta el firme y seguro edificio del conocimiento.

No obstante, nuestra intención en este estudio es defender que la declaración de Los Principios no significa que en el corpus doctrinae de Descartes no se halle un interés y una profunda reflexión o meditación acerca de la moral. Nos apoyaremos, de hecho, en evidencia textual, y metódica, la cual indica inequívocamente que Descartes promueve criterios, valores y prácticas morales.

A modo de preámbulo, anotamos las siguientes referencias:

- En su metáfora del árbol del conocimiento, en el Prefacio de los Principia (1643-44), Descartes señala que «Los patrones morales», son «el

1 P. Chiuminatto: Fundamentos para una estética cartesiana. Universidad de Chile, Tesis doctoral inédita, 2007.

2 Ibíd., 82-141.

3 J. Cottingham: Dicionário Descartes. Jorge Zahar Editor, Rio de Janeiro 1995. 
más alto y más perfecto sistema moral, el cual presupone un conocimiento completo de las otras ciencias y constituye el grado último de la sabiduría (le dernier degré de la sájese)»"

- El autógrafo de Descartes, Andrien Baillet, sin embargo, ha indicado que «la más importante de sus obras póstumas es el tesoro inestimable de sus cartas». Opina que en esta correspondencia, Descartes trata sobre las cuestiones más importantes de la moral (sin duda también de la física, de la medicina y de la matemática) ${ }^{5}$.

- Siguiendo la observación de Baillet, efectivamente hallamos reflexiones morales precisas de Descartes en sus cartas a Elisabeth, a Chanut, a Cristine. En la carta que escribe a Elisabeth (el 18 de Agosto de 1645), propone a la Princesa revisar la doctrina estoica del De Vita Beata de Séneca. Pero cuestiona qué es lo que quiere decir «vivere beate». Significativamente, le hace ver a la Princesa que para «vivre heureusement» hay que conocer las cosas que nos pueden dar contento supremo, y esas cosas son las que dependen de nosotros mismos, es decir, la virtud y la sabiduría.

- En otra de las cartas a Elisabeth (del 18 de Septiembre de 1645), continúa examinando críticamente la doctrina moral de Séneca; se declara, en parte, de acuerdo con Zenón, al considerar la virtud como el único bien que posee cada hombre visto individualmente; pero difiere de la posición estoica griega clásica al considerar que entre todos los bienes que se puede poseer, la virtud es lo único que depende enteramente del libre arbitrio; define aquí la virtud en el contexto de su segunda regla de la moralidad del Discurso, pero en términos anteriormente desconocidos, esto es: «que él debe tener una resolución firme y constante para llevar a cabo lo que le recomiende la razón sin ser distraído por sus pasiones o apetitos». La virtud, así delimitada, consiste precisamente en esta «resolución». Y continúa explicando esta resolución como «el poseer una voluntad firme y constante de poner en acto todo lo que juzguemos ser lo mejor, y emplear toda la fuerza de nuestro intelecto para juzgar bien ( $a$ en bien jugar) $»^{6}$. Allí mismo, extiende largamente su reflexión sobre la

R. Descartes: Principles of Philosophy, Preface, edición inglesa de J. Cottingham, R. Stoothoff y D. Murdoch, The Philosophical Writings of Descartes. Cambridge University Press, New York 1984-1992, vols. I, II, III (en adelante, CSM, a menos que hagamos referencia a otras ediciones); y paralelamente R. DESCARTES: Oeuvres de Descartes, editada por C. Adam y P. Tannery, Vrin, Paris 1964-1976, 11 vols. (en adelante, AT).

5 A. Baillet: La Vie de M. Descartes. Horthemels, Paris 1691, vol. II, 400-428.

6 Descartes a Elisabetta (18 de Agosto de 1645), en G. Belgioioso (ed.), René Descartes: Tutte le Lettere 1619-1650. Il Pensiero Occidentale, Milano 2005, 2071. En otra anterior carta a Elisabeth (del 4 de Agosto de 1645) ya había subrayado que "C'est la fermeté de cete résolution [d'exécuter tout ce que la raison nous conseillera], que ie croy devoir estre prise pour la vertu, 
virtud, pero particularmente destacando su relación con la pasión, el apetito y el placer. En cambio, en su carta a la reina Cristina del 20 de noviembre de 1647 (y en otra a Chanut del $1^{\circ}$ de Febrero de 1647) relaciona el bien supremo de cada individuo con todas las virtudes, o como él dice, «con lo que está en mi poder». Así, afirma:

El bien supremo de cada individuo [...] solo consiste en una voluntad firme para hacer el bien y el contento que esto produce. Mi razón para decir esto es que no puedo descubrir otro bien que parezca tan grande o que esté enteramente dentro del poder de cada hombre [...] solo queda nuestra voluntad que está absolutamente a nuestra disposición. Y no veo que sea posible disponerla mejor que por una resolución firme y constante para llevar a cabo todas las cosas que uno juzga ser lo mejor, y usar todos los poderes de la propia mente para encontrar cuál sea esto. Esto por sí mismo constituye todas las virtudes; solo esto realmente merece gloria y premio, solo esto produce el más grande y sólido contentamiento en la vida. Concluyo, por tanto, que es esto lo que constituye el bien supremo ${ }^{7}$.

Parece claro, sin embargo, desde Septiembre de 1645, escribiendo a Elisabeth, que Descartes se muestra decidido a examinar a fondo la naturaleza, el orden y «el uso» de las pasiones del alma en relación a la virtud. ${ }^{8}$

Nos parece que es en su obra final $-\mathrm{y}$ por cierto posterior a la intensa correspondencia mantenida por años con Elisabeth-el Traité des passions del' âme o simplemente Les passions de l' âme (1649), donde Descartes desarrolla lo que él mismo considera que es «el aspecto más importante de nuestra naturaleza» y que «le cabe al filósofo moral entender»: es decir, la base fisiológica y la dinámica psicológica de las emociones que surgen en el alma cuando es afectada por el cuerpo.

Por otra parte, de manera significativa, el elenco de virtudes de Descartes no es igual al de Aristóteles, Tomás de Aquino y Suárez, así también difiere en el acento de su explicación de por qué las virtudes

bien que ie ne sçache point que personne l'ait iamais ainsy expliquée»; AT, IV, p. 265, 19-21. "Quisquis enim firmam et efficacem habet volunt A. T.em recte semper utendi sua $r A$. T.ione, quantum in se est, idque omne quod optimum ese cognoscit exsequendi, revera sapiens est, quantum ex natura sua ese potest; et per hoc unum, justitiam, fortitudinem, temperantiam, relisquasque omnes virtutes habet, sed ita inter se conjunctas, ut nullae supra caeteras emineant»; Principia, Epistola dedicatoria, AT, VIII 1, pp. 2, 25-3, 4.

7 R. Descartes: Carta a Cristina (20 de Noviembre de 1647), AT, V 83; CSM, p. 325.

8 Para un estudio comparativo de la noción de virtud en Suárez y Descartes, véase G. BuRLANDO: "La passione nella vita virtuosa: etica di Suarez e Descartes", inédito (en prensa). 
morales son buenas. No tiene interés en las virtudes viriles de los griegos, sino en una virtud en especial, más bien radiante, «clave y el remedio para las pasiones», que sirve para «la unidad en la vida moral», y también para la vida social o la vida en comunidad. Para Descartes todo depende de la générosité. El peso y alcance semántico de esta noción es discutida por Descartes en Las Pasiones, donde la interpreta como alternativa de las virtudes heroicas y políticas de las éticas helénicas antiguas.

La hipótesis del presente estudio es que las meditaciones morales de Descartes incluyen una doctrina de las pasiones del alma y una concepción de la vida, ambas intrínsecamente vinculadas. Nuestro propósito será entonces: $1^{\circ}$ ) mostrar que, tras el análisis del corpus cartesiano, es posible reconstruir aspectos centrales de su meditación moral: que su meditación moral incluye una doctrina innovadora de las pasiones. $2^{\circ}$ ) Mostraremos que para Descartes ethos y pathos están vinculados; que este vínculo se hace explícito en sus ideas del conocimiento práctico, esto es, de una praxis que se identifica con el «ejercicio de la virtud»y del «vivre heureusement». $3^{\circ}$ ) Concluimos respondiendo a la pregunta ¿Dónde descansa la moralidad en Descartes? ¿Es para él un asunto de la pura razón? ¿Un asunto más allá de la pura razón? ¿Uno de conceptos, de juicios, de carácter, de educación, de acción y conocimiento práctico o uno de propiedades intrínsecas de las cosas o propiedades de los agentes humanos, o bien de una cierta conexión entre varios de estos?

\section{Pasiones del alma}

Lo que pronto se hace evidente en el estudio de la obra principal de Descartes es que la reflexión moral no parece poseer la unidad que tan notablemente posee su física y metafísica. Por una parte, sus meditaciones morales se constituyen progresivamente y en muchos tiempos, contrariamente a la física, casi íntegramente contenida en el Tratado del Mundo (1664) y a la metafísica completamente expuesta en las Meditaciones (1647); por otra parte, ella no parece conducir a un fin o resultado que la certeza aclarará a cambio de las etapas anteriores y hará de ellas los momentos de una elaboración definitiva.

Comentaristas de Descartes han coincidido en aceptar que su filosofía gira en torno al problema del conocimiento, y que no encuentra en la moral más que la ocasión circunstancial para imprimir las marcas conceptuales de las clásicas presentaciones sobre física o metafísica 
escritas por él ${ }^{9}$. No se encuentra en Descartes un tratado consagrado únicamente a la moral, como en Aristóteles o Kant, en quienes constituye una parte esencial de su sistema filosófico. El único tratado que puede cumplir con esta función es efectivamente el Traité des passions del' âme (1645-6) publicado en 1649, donde él mismo declara que se considera un filósofo natural y no un filósofo moral ni un retórico. Veremos que metodológicamente y en comparación al tratamiento de las pasiones en las doctrinas medievales, Descartes, efectivamente, no las aborda como poeta místico o médico espiritual (del Medioevo judíoislámico) ${ }^{10}$, tampoco como tradicional moralista (del Medioevo cristiano).

La célebre tercera parte del Discurso (1637) expone la máxima de una moral provisional, dictada, le parece más, por el deseo de estar en regla con las autoridades temporales y espirituales que por auténticas y profundas preocupaciones filosóficas. Con excepción de las cartas a Elisabeth, a Chanut y a Cristina donde efectivamente profundiza en las cuestiones tradicionalmente morales, como las del bien soberano y de la virtud, aunque esto con ocasión de las preguntas que le formulan sus corresponsales y dentro de los límites de un intercambio epistolar privado.

Como ya hemos notado la Correspondencia de Descartes con la princesa Elisabeth de Bohemia tuvo como resultado su último libro, el Traité de les Passions del'Ame. En el mismo prefacio Descartes declara su intención de explicar las pasiones «solamente como filósofo natural [o médico], no como retórico... ni moralista» (Les Passions, I art. 327) ${ }^{11}$. A primera vista su declaración ha dejado perplejos a la mayoría de sus comentaristas: parece no corresponder al tratamiento moral que él ofrece en la mayor parte del libro, dada su intención de entenderlas y conducirlas en vista de la felicidad. El significado de la declaración de Descartes se justificaría por el tipo particular de exposición que él hace de las pasiones. En general, gira el eje aristotélico-tomista al situar las pasiones no en la pura alma sensible, realmente distinta del alma racional

9 Cfr. J. CotTingham: Dicionário Descartes, ya citado; J. MARShall: Descaretes's Moral Theory. Cornell University Press, Ithaca and London, 1998; P. GUENANCIA: Lire Descartes. Gallimard, Paris 2000; A. AgAzZI: Historia de la filosofía y la pedagogía, Tomo II, Editorial Marfil, Valencia 1966.

10 Cfr. la obra de Kitâb al-tibb al-rûhânî, El libro de la medicina espiritual, citada por R. Ramón Guerrero: "Del amor en la filosofía Árabe”, en G. Burlando (ed.), De las pasiones en la filosofía medieval. LOM, Santiago de Chile 2009, 155.

11 Utilizamos y traducimos tanto desde la edición inglesa de The Passions of the Soul en CSM vol. I; como también desde la edición francesa Les Passions del'Ame, ed. RodisLewis, G. J. Vrin, Paris 1991 (en adelante, Les Passions). También citaremos la edición española de Las Pasiones del Alma. Edición, introducción y notas de Julián Pacho, Biblioteca Nueva, Madrid, 2005. 
y de la voluntad, sino dentro de la res cogitans y definirlas - no como apetitos- sino como un tipo de pensamientos, diferentes a todos los otros pensamientos o cogitaciones puras, porque por una parte, y más bien, son «percepciones, sensaciones o emociones del alma [en general] que refieren particularmente a ella», pero por otra parte, "pueden ser causadas, mantenidas y reforzadas por algún movimiento de los espíritus animales», es decir movimientos del cuerpo (Les Passions, I art. 27). Las pasiones tienen, así, una estructura híbrida, son a la vez pensamientos, ideas, percepciones, modos de conocimiento presentes en nosotros, y acciones del cuerpo recibidas por el alma, por eso «no es nuestra alma la que las hace tal como son» (Les Passions, I art. 17). En el tratamiento de las pasiones Descartes da inicio a una psicología psicosomática ${ }^{12}$.

Pero las pasiones no son enfermedades del alma, o «perturbaciones del alma» comparables a los cuatro principales vientos en el origen de las tempestades ${ }^{13}$, tampoco son fuerzas aniquiladoras como sostienen los filósofos antiguos y medievales (árabes, judíos) para quienes el cuerpo y sus deseos estigmatizan el pecado y la corrupción de la naturaleza humana. Descartes, al examinarlas como físico, las encuentra «todas buenas», en tanto que le parece impensable que la naturaleza las haya puesto en el hombre sin darles algún uso. Pero, justamente, su bondad o malignidad reside en su uso, bueno o malo. Descartes presupone al hombre inocente (Hobbes o Kant lo presuponen malvado o desprovisto de santidad, respectivamente) y al mismo tiempo lo hace responsable del error como de la verdad, del mal y del bien que hace a los otros y a sí mismo.

Las pasiones, para Descartes no son productos de la interrupción de la unión entre alma y cuerpo, sino al contrario, son efectos necesarios de los movimientos de los «espíritus animales» ${ }^{14}$ de un mecanismo corporal

12 Cfr. R. Descartes: Las Pasiones del Alma. Edición, introducción y notas de Julián Pacho, Biblioteca Nueva, Madrid 2005, 43.

13 F. SuÁreZ: Disputaciones Metafísicas, edición y trad. de S. Rábade, S. Caballera y A. Puigcerver, Gredos, Madrid 1960-1966, 7 vols., VI, q. 5, a.1.

14 Los «espíritus animales» no son espíritus en el sentido metafísico del término, sino cuerpos muy pequeños que se mueven muy rápidamente (Les Passions, I art. 10). Se generan en el cerebro constituyendo las partes más «sutiles» de la sangre y pueden penetrar las paredes del sistema circulatorio y pasar de él a los nervios. Son la fuente mecánica de energía del movimiento corporal y juegan un papel esencial en la teoría del estímulo y la sensación. La tesis principal de Descartes es que las pasiones del alma se originan en las alteraciones corpóreas, las cuales son comunicadas por los espíritus animales a la glándula pineal y por consiguiente, causan estados afectivos en el alma - afecciones dirigidas al alma misma en su totalidad y no al cuerpo. Dado que las pasiones se originan en el cuerpo pero son recibidas por el alma, representan la nueva tendencia psico-física o psicosomática de la psicología de Descartes. Por lo mismo no 
y por lo mismo de una institución de la naturaleza que el hombre encuentra siempre ya ahí. Las pasiones están ligadas al mismo límite entre alma y cuerpo, son signos de la unión del alma con el cuerpo ${ }^{15}$, y como todo signo, requieren de un comportamiento, una conducta, una actitud y no de un desciframiento, de una interpretación, de un análisis.

\section{Búsqueda de verdad y contento: Vivre heureusement}

Descartes propone diversas perspectivas en el estudio que hace de las pasiones. Las considera según su génesis — luego elabora una lista de las pasiones primitivas, según su orden- y según el criterio de simplicidad que él aplica siguiendo su propia indicación metódica; también las considera según sus afinidades psicológicas. Esta variedad de perspectivas, que pueden hacer más problemática la unidad del Traité que la cuestión del origen de las pasiones, como hace notar Pierre Guenancia $^{16}$, no es la cuestión principal a los ojos de Descartes y que la sola y auténtica respuesta a una pasión del alma (que es una acción del cuerpo) es una acción del alma (y así, una «pasión» del cuerpo) si se puede así decir, porque se está empezando a ser consciente ${ }^{17}$. En la

es de extrañar que la II parte del tratado está enfocada a distinguir las pasiones y considerarlas por sus efectos en términos fisiológicos, de ahí la declaración inicial de Descartes que las explicará como filósofo natural.

15 Dolor y placer: hambre, sed, calor, olores, pasiones, son para Descartes, ideas del tipo de sensaciones provenientes de la unión del espíritu y el cuerpo; cfr. Meditaciones Metafísicas con Objeciones y Respuestas, traducción de Vidal Peña, Alfaguara, Madrid 1977, Meditación VI (en adelante, Med. Met.). Para estudiar qué más hay sobre sensación en Descartes, véanse sobre la idea de frío: 'Cuartas Objeciones', pp. 145, 6; 'Cuartas Respuestas' (Med. Met., pp. 162-4). Sobre la idea de sensación y los grados de la sensación, véase las Sextas Respuestas (Ibíd., pp. 294-5). Filósofos contemporáneos como Russell, Ryle, Reid y Rorty han acreditado que Descartes nos introduce efectivamente de manera innovadora a la Filosofía Moderna, porque admite un modo de ideas del tipo de sensaciones. Estas ideas son sensaciones ordinarias, experiencias sensoriales o datos de los sentidos (sense data) que son intencionales o representaciones de cosas materiales externas. De tales sensaciones nosotros estamos directa o inmediatamente conscientes. Para Descartes las sensaciones son propiedades de nuestras mentes, las cuales nos proveen de conocimiento del mundo material externo.

16 P. GuENANCIA: Lire Descartes. Ed. Gallimard, Paris 2000, 201 ss.

17 En las 'Segundas Respuestas' y en Los Principios de la filosofia, Introducción, traducción y notas de G. Quintás, Alianza, Madrid 1995, Parte I 9 (en adelante citado como Los Principios), Descartes define su amplia noción de pensamiento, los «que están en mi» (y dentro de lo cual caen sensaciones y pasiones) en términos de consciencia o de consciencia inmediata. «Pensamiento» (en latín cogitatio, en francés la pensée) es «eso que está en mí de tal manera que soy inmediatamente consciente de ello», Los Principios 
exégesis de Guenancia que aquí seguimos, efectivamente «las acciones del alma son justamente sus deseos (volontés). Pero un deseo no se opondrá a lo involuntario, como son los movimientos corporales. El alma no se opone a la sequedad de garganta, sino al deseo de beber. Un deseo no se puede oponer a tener un deseo, lo cual siempre implica algo involuntario $y$, por consiguiente, algo en que no hay consentimiento» ${ }^{18}$. Por eso la principal acción del alma consiste en resistir a aquello que las pasiones la dispongan y no a impedir las pasiones, puesto que el alma no las causa. Sin duda es la conciencia que tiene Descartes de la necesidad de las pasiones en un alma ligada al cuerpo y de su carácter involuntario y mecánico en sus procesos de formación lo que lo hace separase de los filósofos moralistas antiguos y ordenar la tabla de las pasiones de un modo novedoso, desde la perspectiva física.

El alma no experimentaría pasiones, si ella no tuviese un cuerpo, y por su cuerpo el alma experimenta el mundo. Aunque también la pasión sea un pensamiento, una idea o una intelección en la que el alma se contempla; solo las representaciones que son acompañadas de una emoción -alteración o intensificación de los movimientos comunes de los espíritus animales- merecen ese nombre, a diferencia de las ideas solas o de las imágenes puras $^{19}$, el alma no las contempla como una cosa exterior a ellas, sino que las siente en el interior.

Parte I 9, p. 26. Confirma esta misma respuesta en carta a Arnauld, 29 de Julio 1648 (CSM, vol. III, p. 357).

18 P. GuENANCIA: Lire Descartes, 215.

19 Las ideas de este tipo son, para Descartes, aquellos de nuestros pensamientos que «son como imágenes de cosas» («tanquam rerum imagines») (AT, VII 37). En algunos pasajes quita el «imagines» y nos dice que «no puede haber ideas que no sean como si de cosas (tanquam rerum)» (AT, VII 44). En la versión francesa de este pasaje nos explica más claramente qué quiere decir que una idea sea tanquam rerum: «no puede haber ninguna [idea] que no parezca representar alguna cosa (ne nous semble representer quelque chose) (AT, IX-1 34-35). Las ideas obedecen a su principio causal como otra interacción entre objeto-cosa-idea. El mismo tipo de principio causal que se aplica al mundo material, se aplica a las ideas. Los objetos son causas de las ideas, ellos están inmediatamente presentes a la mente y la mente está directamente consciente de las ideas; las ideas son causadas por el mundo externo, según Descartes. Pero en Med. Met., Meditación III, Descartes advierte diferencias entre ellas, escribe: «Mas se me ocurre aún otra vía para investigar si, entre las cosas cuyas ideas tengo en mí, hay algunas que existen fuera de mí. Es saber: si tales ideas se toman simplemente como cierto modo de pensar, no reconozco en ellas diferencias o desigualdad alguna, y todas parecen proceder de mí de un mismo modo. Pero al considerarlas como imágenes que representan unas una cosa y otras otra, entonces es evidente que son muy distintas unas de otras. En efecto, las que me representan substancias son sin duda algo más, y contienen (por así decirlo) más realidad objetiva, es decir, participan por representación de más grados de ser o perfección, que aquéllas que me representan sólo modos o accidentes» (CSM, vol. II, p. 35. 
Y cuando la pasión presente es particularmente fuerte, como la indignación, la cólera, el odio, los celos, el alma no es tan distinta de la emoción que siente y que le indigna. En casos como estos el alma no se pertenece más, no consigue separarse de lo que le agita y mueve, aun menos puede contemplar desde el exterior lo que le afecta, como lo hace en el ejercicio de consciencia y reflexión sobre sí misma. La pasión tiende a suprimir la distancia entre el yo y eso que le es exterior. Por eso el «remedio» a las pasiones no es extirparlas del alma, suprimirlas - lo que significaría suprimir al hombre- sino que restituir la distancia que tiende a suprimir y asegurar que el yo no se confunda con ellas, y por ellas, con las diversas situaciones que está dado a encontrar. Así, el carácter asociativo de la pasión se puede oponer a la acción separadora del entendimiento (a su reflexividad). Por una parte, esto se debe precisamente a la relación, instituida por la naturaleza, entre un movimiento del cuerpo y un pensamiento que define a toda pasión, y a diferencia del vicio y la virtud, los cuales no son acompañados de ningún movimiento de los espíritus animales, de alguna emoción particular. Por otra parte, se debe a la relación que las pasiones instauran entre el yo, los otros, y el mundo.

La primera de estas relaciones constituye «el principio» de la explicación cartesiana de las pasiones: «a saber, que existe tal vinculación entre nuestra alma y nuestro cuerpo que, cuando hemos unido alguna vez un acto corporal con un pensamiento, en lo sucesivo ya no se nos presenta nunca uno sin el otro» (Les Passions, art. 136, p. 148). Las uniones o asociaciones que perduran son de origen inconsciente en su mayoría. Son las asociaciones habituales entre tal tipo de objeto y tal emoción (por ejemplo, la fobia a los gatos, u otras). En este sentido toda pasión posee una historicidad única que a su vez explica su origen y su fuerza. Y esa historicidad, este hábito, es lo que la razón encuentra desde ya constituida y, es ante esa historicidad que la razón debe elaborar ejercicios y prácticas para disociar las representaciones de emociones comunes que las acompañan.

La segunda relación, se puede decir, es la de la vida misma. Las pasiones son relaciones compuestas (híbridos) de alma/cuerpo, límites y signos que enseñan al alma sobre la utilidad o daño de las cosas para el cuerpo al que ella está unida. Por eso que «todas estas pasiones (primitivas) se refieren al cuerpo y solo afectan al alma en tanto que ésta está unida a aquél. De suerte que su función natural es incitar al alma a consentir y contribuir a las acciones que puedan servir para conservar el cuerpo o hacerlo de algún modo más perfecto» (Les Passions, art. 137). Así, limitada por la finalidad general de la vida, la pasión es distinta de la razón, del entendimiento, del juicio cuyo oficio es examinar vía pasión el 
justo valor de cada cosa y de regular nuestros deseos, o de limitar a la ilimitada voluntad según la importancia del bien que nosotros nos representamos.

Aunque la principal relación que el alma mantiene con todas las cosas es una relación de conocimiento; es la unión con el cuerpo lo que introduce la reducción de todas las cosas a la utilidad (bien) o a lo nocivo. Pero esta acción no es nunca tal que anule totalmente el poder que el alma tiene de representar las cosas a través de las ideas y de distinguir el valor o la perfección de lo que ellas representan, de la importancia que las mismas cosas tienen en la vida y en las pasiones. En Descartes la objetividad del juicio nunca está completamente separada de los intereses de la vida y de las pasiones. La voluntad, principio y solo principio de la conducta ética, queda siempre subordinada al entendimiento y a las representaciones que se limita a distinguir las unas de las otras. No es el valor que evalúa, es el valor o la perfección de las cosas representadas que mueven a la voluntad, y mientras estas perfecciones sean más grandes y las representaciones más distintas, más fácil y libre será el ejercicio de la voluntad. El entendimiento concibe y conoce, la voluntad elige y se determina, eso es todo ${ }^{20}$.

20 Descartes coincide, en general, con la tradición que adopta Suárez para explicar la voluntad. Suárez, a su vez, como hemos ya estudiado (G. BURLANDO: "Ética de la elección libre en F. Suárez", Enciclopedia Iberoamericana de Filosofía, vol. 24 Filosofía Medieval. Trotta, Madrid 2002) adopta y aúna por una parte, las perspectivas de Anselmo, Scotus y Ockham para quienes la voluntad consiste en un deseo interno del agente, y este es un deseo de propio bienestar; y, por otra, la humanista del Renacimiento. Esta última defiende la autonomía de la voluntad y su acción libre. La libertad humana para los humanistas es un poder del hombre para generar sus propias leyes morales y tomar decisiones racionales solo sobre la base de dichas leyes, independientes de toda influencia externa. Igualmente es pensada como en una dimensión interna de decisión absolutamente autónoma e inviolable. En las Disputaciones Metafísicas, Suárez distingue dos roles bien definidos y ligados entre sí de la voluntad humana. Uno, tiene que ver con lo que la voluntad humana es. La naturaleza de la voluntad no la expresa en los términos tomistas tradicionales, como 'apetito intelectual', ni en los términos de D. Scotus como un puro «poder volitivo», sino más bien en términos de un estado mental interno que él denomina de «deseo vital elicitivo» (desiderium elicitum vitaliter). El otro rol, tiene que ver con cómo funciona la voluntad, es decir, como un solo poder (activo-pasivo) indiferente y capaz por sí mismo de producir el acto mental más perfecto, es decir, la elección libre. En las Med. Met., Meditación IV, Descartes, describe ontológicamente la voluntad humana como la misma facultad de elegir o liberum arbitrium. La operación de la voluntad, sin embargo, es distinta de la operación del entendimiento, cuyo poder Dios me ha dado «para discernir la verdad (y) es limitado», mientras que la voluntad «se extiende con mayor amplitud que el intelecto». En Los Principios I 38, explicando el uso incorrecto del libre arbitrio, y la esencia del error, Descartes insiste en distinguir la propiedad de «nuestra voluntad, que tiene un vasto alcance (más amplia y hasta infinita)», por tanto, al igual que la voluntad 
El entendimiento no es una facultad electiva, la voluntad no es una facultad deliberativa. Por cierto, la voluntad no puede determinarse a elegir más que de entre las cosas que el entendimiento tiene alguna idea, pero podemos tener todas las ideas claras y distintas deseables, sin embargo, ser incapaces de hacer cualquier acción. Todas las reglas de la moral de Descartes, provisoria o perfecta, se reducen a una sola: hacer lo que se juzga ser lo mejor ${ }^{21}$.

de Dios, y por su amplitud es «puissance infini». Pero mientras el poder o puissance de Dios es ya sea un puissance con "potencia infinita» (puissance infinie) (un poder o fuerza inagotable) para existir (Gilson) o también, como explícitamente declara Descartes, un puissance «de hacer una infinidad de cosas cuyas causas sobrepasan el alcance de mi espíritu», y que «siento incomparablemente mayor en Dios que en mí». Por lo cual, el poder de la voluntad humana «consiste solamente en que podemos hacer una cosa, o no hacerla» y esta es la experiencia de la libertad (o la de «una voluntad lo bastante amplia y perfecta, pues claramente siento que no está circunscrita a límite alguno») de manera que es la voluntad libre la que «me hace conocer que yo llevo la imagen y semejanza de Dios». Es en ella que yo experimento esta ilimitación en la que tengo la idea positiva y totalmente verdadera (Med. Met. Meditación IV, p. 47-48). Por otra parte, desde la perspectiva de la moral, en el contexto de la pregunta escolástica por el valor de la voluntad libre, si acaso es buena, la respuesta de Descartes es absolutamente No! Ella, más bien, es indiferente.

21 «Porque si cualquiera vive de tal modo que su conciencia no pueda nunca reprocharle por haber caído en hacer algo que juzga ser lo mejor (lo que aquí llamo 'perseguir la virtud'), recibirá de esto una satisfacción que tiene tal poder para hacerlo feliz que los más violentos asaltos de las pasiones nunca tendrán poder suficiente para perturbar la tranquilidad de su alma» (Les Passions, art. 148). En relación las reglas de la acción libre, para Suárez en cambio, si se trata de la voluntad libre (de Dios), Él no basa su elección en un juicio de lo mejor. Dios no funda su elección del mundo actual en un juicio (suyo anterior) basado en el «mejor mundo posible». Argumenta así: «entre estos cielos y otros completamente iguales (y también con respecto a las demás cosas), eligió crear éstos más bien que otros, lo cual no puede A. T.ribuirse a un juicio desigual, ya que ni por parte de ellos ni por parte de Dios hay razón alguna en la que pueda fundarse un juicio semejante que sea verdadero; por consiguiente, esa elección previa nace de la libre determinación de la voluntad divina. [...] incluso [...] considero más probable que la voluntad no se determina necesariamente a lo que es mejor en virtud del juicio. Se demuestra porque por el solo hecho de que ninguna de las dos cosas se propone como necesaria, la voluntad puede no amar a ninguna; luego también puede amar indiferentemente a una de ellas, prescindiendo de la otra. Y, en opinión de muchos, esto es necesario en la voluntad divina, ya que pudo hacer cosas mejores que las que hizo, y sin embargo, no quiso hacerlas [...]. Por consiguiente, el juicio acerca de un juicio mejor o más útil no determina a la voluntad a quererlo», F. SUÁREZ: Disputaciones Metafísicas, XIX 6 13) (Agrego cursivas). La función del juicio, según Suárez, es exhortar prácticamente a la voluntad a desear un objeto bueno, pero la voluntad, según su libertad, todavía puede no amarlo, y no-solo no amarlo sino incluso odiarlo. Así pues, las mejores y más útiles razones no son fundamento suficiente para la acción libre. Dios no parece ser un meliorista à la Descartes, ni à la Leibniz. Elige crear este mundo simplemente porque Él quiere. 


\section{Lugar de la moral: deseo propio de contentamiento}

De manera innovadora frente al escolasticismo, Descartes distingue seis pasiones primitivas: asombro, amor, odio, deseo, alegría y tristeza. Las demás son compuestas de estas o bien subespecies de ellas (Les Passions, art. 69). Las pasiones operan de una manera común: «el efecto principal de todas las pasiones humanas es que ellas mueven y disponen al alma a querer las cosas para las cuales ellas preparan al cuerpo». Así, las pasiones son en primer lugar estados motivadores internos que disponen al alma a querer acciones específicas: «el sentimiento de temor mueve al alma a querer huir, el de coraje a querer pelear, y de modo similar con los demás» (Les Passions, art. 40). Pasiones diferentes resultan de los efectos de movimientos diferentes en la glándula pineal; y estos, asume Descartes, han sido ordenados por Dios por el amor de preservar el cuerpo humano: «la función de todas las pasiones consiste solamente en esto, que ellas disponen nuestra alma a querer las cosas que la naturaleza estima útil para nosotros, y persistir en este querer; la misma agitación de los espíritus que normalmente causa las pasiones también dispone al cuerpo a hacer movimientos que nos ayudan a conseguir estas cosas» (Les Passions, art. 52).

Descartes piensa que las pasiones deben ser últimamente reguladas por los poderes de la razón. En palabras suyas: «Ce que je nomme les propres armes [de la volonté] sont des jugemens fermes et determinez. touchant la connoissance du bien et du mal, suivant lesquels elle a resolu de conduire les actions de sa vie») ${ }^{22}$. A pesar de su posición racionalista, al final del Traité de les Passions, Descartes admite que quienes son movidos «más hondamente por las pasiones son capaces de gozar de los placeres más dulces de esta vida» (Les Passions, art. 212). Considera que «el principal uso de la sabiduría descansa en enseñarnos a ser maestros de nuestras pasiones y a controlarlas con tal destreza que los males que ellas causan son totalmente tolerables e incluso llegan a ser una fuente de alegría». Definitivamente llega a juzgar que «todo el bien y el mal de esta vida depende de las puras pasiones» (Les Passions, art. 212).

Además del papel que las pasiones cumplen específicamente en la conservación del cuerpo, también contribuyen a la felicidad humana. Insiste como vimos en líneas anteriores en que la felicidad depende de las pasiones. Su perspectiva moral es que las pasiones, particularmente el

\footnotetext{
22 Las «propias armas» de la razón, como dice él, en contra de su mal uso y exceso son «los juicios firmes y determinados [que] conllevan el conocimiento del bien y el mal, que el alma ha resuelto seguir al guiar las acciones de su vida», Les Passions, art. 48; AT, XI, p. 367, 5-9.
} 
amor y la alegría, conforman una parte valiosa de la vida humana normal, que el gozo de ellas es consistente con la felicidad que es producto natural de la acción virtuosa, pero que la felicidad se puede tener incluso en presencia de las pasiones dañinas tales como la tristeza o el pesar. La felicidad, define Descartes es «un contentamiento perfecto de la mente y una satisfacción interion» o la «satisfacción y el placer» que acompaña la práctica de la virtud (Les Passions, art. 148).

Pero ¿en qué consiste este «contentamiento perfecto de la mente», de qué se trata «la satisfacción interior» o la «satisfacción y el placer que acompaña la práctica de la virtud»? La moral cartesiana está, como hemos mostrado, vinculada profundamente a la vida. A esta misma vida en la que debemos suspender la experiencia y sus enseñanzas para conocer cuáles son en ellas mismas, y no en relación a nosotros, las cosas de las cuales nuestra mente tiene ideas claras y distintas.

La universalidad, que Descartes adhiere a su proyecto de las Regulae y que él reafirma con el nombre de sagesse en el Prefacio de los Principia (1647) se opone a la parcelación de las disciplinas y a eso que se relaciona a la mente humana en tanto unidad indivisible. Su función verdadera no consiste en «resolver tal y tal dificultad de escuela» sino en demostrar que la voluntad da forma a lo que se determina «en cada ocasión de la vida [...] la opción de hacer» ${ }^{23}$. Hay hombres, dice Descartes, cuyo deseo de saber aún no se ha ahogado: de ver claro en la acción y de caminar con seguridad en la vida ${ }^{24}$. El tema de la vida, de la conducta de la vida, del comportamiento para con los otros, sus creencias, sus costumbres, es un tema constante en el Discurso y que se anuncia tan pronto en el pensamiento de Descartes con la pregunta «Quod vitae sectabor iter?» ${ }^{25}$. ¿Qué camino debo seguir en la vida? Las reflexiones sobre el «sí mismo» en estas páginas tan célebres parecen constituir la enseñanza esencial ética de un hombre que ha encontrado en el contentamiento o satisfacción que el frecuentar la escuela y los maestros no le han dado. En el fondo el método es el título oficial y el objetivo de este cuidado de sí que nos parece caracterizar y contener el pensamiento moral de Descartes. De lo contrario, no se comprende bien por qué Descartes une muy a menudo la búsqueda de la verdad, o la objetivación de las ciencias con el intento de satisfacción; o ¿Por qué la verdad está en su mente no separada del bien, ya sea como agrado, satisfacción o contentamiento? En mi parecer, porque la elaboración de su Obra y la solemnidad de la

\footnotetext{
23 R. DESCARTES: Rules for the Direction of the Mind (CSM) vol. I, p.10.

24 R. DESCARTES: Discourse on the Method, I (CSM) vol. I, p. 115.

25 Descartes cita el comienzo de la Oda siete del poeta romano del siglo IV d. C. Decius Magnus Ansonius en Experimenta o Observations (CSM) vol. I, p. 4.
} 
decisión en la que ha querido responder a un llamado venido desde lo más alto que él constituye el verdadero y único compromiso de su vida.

De aquí se puede notar que la moral de Descartes está efectivamente bien fuera de su sistema filosófico, pero es condición incondicional de ese mismo sistema. Descartes repite a menudo que las acciones de la vida no pueden igualar la certeza de los objetos del entendimiento, y que será vano, posiblemente dañino, esperar para la determinación del actuar, las que indican un camino exento de riesgo, pero no dice que no hay certitud que pueda aclarar y anular su indeterminación intrínseca por una determinación o solución que la mayoría de la gente espera que provenga de la fortuna, pero que él, como filósofo, sabe encontrar en la fuente de una voluntad que tiende al bien o, al menos, a lo mejor.

Pero en verdad la satisfacción del alma depende de la posesión de la certeza. La moral de Descartes no se podría reconocer en la satisfacción del fin último de la vida bien conducida si no estuviera garantizada por una certeza en que no puede dominar ciertos peligros de la vida, y por consiguiente, que es una vida independiente. La satisfacción o contento, entonces, resulta del acuerdo entre los juicios del entendimiento y las acciones de la voluntad. Esta noción central en el pensamiento cartesiano marca indisociablemente sus dos temas constantes: la búsqueda de la verdad y la conducta en la vida. Esta es la razón de por qué la opción por la actividad filosófica parece a Descartes, en el contexto del Discurso y en la carta-prefacio de los Principia, lo único que puede procurar al alma satisfacción, contento duradero, aclarado por la luz pura y constante de la certeza y la verdad. En los últimos escritos de Descartes la filosofía parece tomar el lugar que el Discurso atribuye con mucho gusto a la medicina (la que hace a los hombres más sabios): se ocupa de regular siempre cualquier tipo de relación del alma y del cuerpo en el sentido de un equilibrio, más que en el de una jerarquía o de una dominación del alma sobre el cuerpo. El dominio del alma sobre el cuerpo se parece más al de un guía conductor que al del poder político de un jefe administrativo.

Vivir con las pasiones requiere habilidad, experiencia, un saber sobre el sí mismo de uno como quien tiene un timón y no la soberbia, el orgullo, la vanagloria y en el fondo, la mezquindad e ignorancia de aquel que tiene deseo perpetuo de poder, de poder de dominio sobre los demás. Por eso la medicina y la filosofía son para Descartes, como para los antiguos filósofos, dos puntos de vista diferentes de una misma realidad, o dos modos diferentes de obtener un idéntico resultado: la salud del alma (conocer la verdad) y la salud del cuerpo deben encontrarse en la parte del hombre que es la unión del alma y el cuerpo. En el Traité des passions como en muchas de las cartas a Elisabeth, 
Descartes no comienza a referirse a la naturaleza del cuerpo, sino a lo que necesita el alma que está unida y forma con el cuerpo «como un solo todo» (comme une seul tout). La moral de Descartes no logra ubicarse estrictamente dentro de la lógica tradicional de la antigua Estoa, sino más bien en un tipo de lógica neo-estoica: todavía obedece a la preocupación por el exceso, pero para vivir feliz no basta con imitar o «seguir la naturaleza»; se trata más bien de conseguir satisfacción y contento personal sabiendo usar nuestra propia naturaleza, nuestras pasiones del alma, nuestro libre arbitrio. Se puede decir que el lugar donde reside la singularidad de las meditaciones morales de Descartes está en que no pone énfasis en el deber, en el hacer lo correcto, en el deseo de descubrir pruebas absolutamente irrefutables de principios morales de los cuales estemos ya convencidos que son verdaderos, tampoco construye una regla de cálculo para medir placer y dolor, ni compila una colección de consejos, de recetas que permitan al hombre vivir bien. A veces su reflexión toma la forma de una exaltación, pero no se reduce a ella. No es cuestión de leyes universales, de prohibiciones, de reglas, tampoco es cuestión de sondear las profundidades del alma humana para revelar sus ulteriores pulsiones. Para Descartes, no es la debilidad del alma la que hace la ocasión de la moral, sino que ella es la sede del cuidado y fortaleza del sí mismo, sin este cuidado personal, sin la vida feliz de la propia mente, la más feliz, no hay conducta feliz para con los otros.

\section{Notas conclusivas}

A lo largo de este estudio hemos corroborado que la Obra de Descartes no incluye un tratado monotemáticamente consagrado a la moral, como existe en la Obra de Aristóteles o Kant, para quienes la moral constituye una parte emblemáticamente esencial de sus sistemas filosóficos. Pero esperamos haber mostrado que esto no quiere decir en absoluto que Descartes no haya hecho profundos y genuinos aportes a la reflexión moral, ya sea en el corpus doctrinae del Discurso del método, el tratado de las pasiones del alma, las Meditaciones metafísicas, las Reglas, o en su correspondencia particular con Elisabeth, Chanut y Cristina. En consecuencia, desde tal reflexión, dirá Guenancia: «la única y profunda verdad de la moral cartesiana es esta: Un hombre que no comienza a regular las relaciones consigo mismo en el sentido de un equilibrio entre sus juicios y sus deseos, no sabrá en adelante regular sus relaciones con los demás» ${ }^{26}$. Por tanto, aquél que no está contento consigo mismo no

P. GuENANCIA: Lire Descartes, 219. 
mantiene relaciones libres, de recíproca estimación, de reconocimiento, pues la insatisfacción que le afecta, también afecta sus relaciones personales y civiles con los otros, lo hace sospechoso, avaro, malvado e inconstante, o al contrario, simplemente digno de admiración.

Sumario: 1. Pasiones del alma; 2. Búsqueda de verdad y contento: Vivre heureusement; 3. Lugar de la moral: deseo propio de contentamiento; Notas conclusivas. 